\title{
From Non-Discursive Qualities of Space to Conscious Design
}

\author{
Kerstin Sailer and Sam Griffiths \\ Space Syntax Laboratory, Bartlett School of Architecture, University College London \\ k.sailer@ucl.ac.uk; sam.griffiths@ucl.ac.uk
}

\section{When designers design...}

When designers, architects and urban planners take decisions on built form, they normally focus on the physical objects they create, be they single buildings, an ensemble of buildings, or whole neighbourhoods. This is to be expected given the training these professionals have received in creating and crafting materials into larger structures, and the specification of the typical client brief with its emphasis on the functional requirements of concrete objects. This focus on the physical has two important implications: first, cities emerge out of a myriad of independent decisions taken by multiple stakeholders over the course of time. Secondly, while physical elements such as walls, ceilings, facades, shapes, volumes and blocks are scrutinised as part of the design process the space in between receives less attention. Formed by the leftovers between buildings, or as the bits and pieces of nothingness between walls, facades and ceilings, space is often excluded from what architects and urban planners designnotable exceptions excluded, see for example ${ }^{1}$. Space is important, however, since it speaks directly to human experience and the everyday acts of occupation of the built world. In this paper we explore why space is a significant element in social practices and how its elusive effects can be conceptualised and talked about using the theoretical and methodological framework of space syntax, which investigates the spatial configuration of architecture and its social affordances (see figure 1). We will discuss how this formal analytic lens provides a way to move towards a more discursive, or conscious design process in the context of the on-going social production and reproduction of the human built environment. 

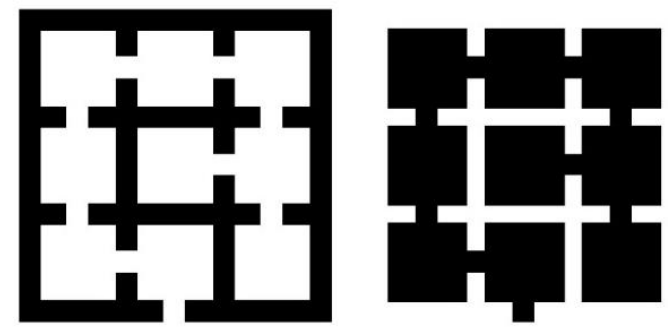

a.
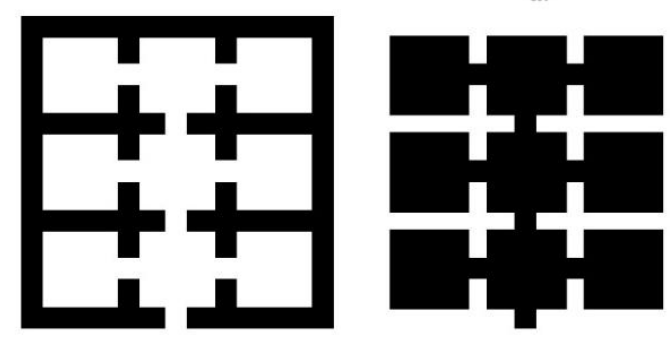

b.
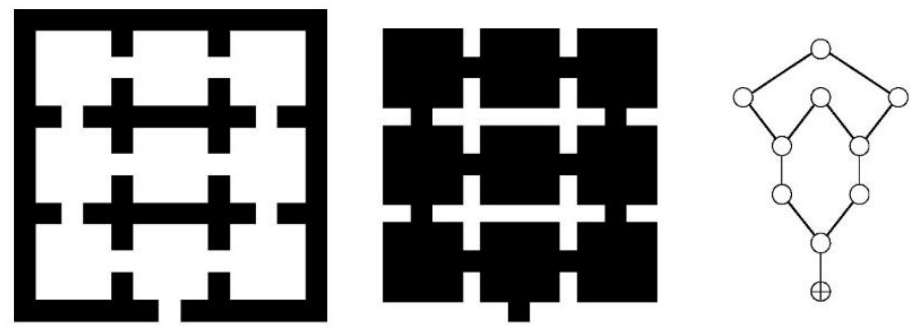

Figure 1: Three ways $a, b$ and $c$ of arranging the same spatial cells into different configurations. In this sense configuration - the way spatial elements are put together - creates social affordances since it has consequences for the human experience of space [Source: Hillier 1996, p. 30]

\section{From spatial practice to spatial configuration}

As human beings, all our experiences of the world and actions in the world have a spatial component, since our bodily existence places us in a material context. Whatever we do, we are somewhere. This embodied nature of our experiences and actions is structured by the environment (hence spaces) around us ${ }^{2}$. Hillier has argued:

"Human behaviour does not simply happen in space. It has its own spatial forms. Encountering, congregating, avoiding, interacting, dwelling, teaching, eating, conferring are not just activities that happen in space. In themselves they constitute spatial patterns." 3

Hillier argues that spatial patterns are tied to activities, and while he does not make an explicit claim on the concept of spatial practices as such (for which see Lefebvre 1991), the implication is clear in his work that 'everyday life' is fundamentally spatial. This view has parallels with Giddens' 4 notions of 'situated practice' and 'practical consciousness'. Giddens defines the domain of social sciences as practice-based. He argues it is:

"(...) neither the experience of the individual actor, nor the existence of any form of societal totality, but social practices ordered across space and time." 4 
The discussion about the spatial nature of the social (sometimes also called 'spatial turn') has become a pervasive theme in social theory since the 1980s. Gregory and Urry for instance, have argued in the field of human geography that spatial structure is not just the arena (or container, as others might call it) inside which social life unfolds, but "rather [...] a medium through which social relations are produced and reproduced" 5 . In the realm of organization theory, a similar approach focussing on everyday behaviours presents the entanglement of the social and material as so called 'sociomateriality' 6,7 . In sociology, an interest in the dynamics of social practices and changes in everyday life ${ }^{8}$ also links back to spatial arrangements as constituting practice 'bundles'. In reacting to the prevailing theoretical articulation ${ }^{9}$ of the co-constitution of the social and the spatial Hillier argues that the "real space of shaped and linked architectural and urban spaces" 10 is often neglected. He objects to theorisations that project the socio-spatial morphologies he assigns to buildings and cities as wholly derivative of abstract socio-economic forces. He counters these, somewhat misleadingly (because it suggests he endorses an opposition of the two), with an argument for 'space first' rather than 'society first' interpretations. It follows that Hillier claims a degree of autonomy for 'spatial configuration' (i.e. the way spatial elements are put together) in the constitution of the social.

\section{Space as configuration - a syntactical perspective}

The apparently straightforward observation that social space is a continuum that flows from one bounded setting to another is the starting point of space syntax theory. The human experience of space, from this perspective, is not static but transcends single spaces and connects them into paths leading from one place to another. Rather than starting from individual experiences, space syntax aims to explain the 'social logic of space' ${ }^{11}$ through spatial configuration and its effects on people and society.

Human actors in space intuitively know how to read space and move about in it, yet explaining those processes and reflecting on them is certainly not straightforward. Hillier argues in his seminal work Space is the Machine ${ }^{3}$ that space is 'nondiscursive', meaning it is hard to talk about discursively using natural language. Space syntax, by contrast, is a morphic language, a method of describing, analysing and representing space to make the configurational qualities of individual places accessible to the design process. As a morphic language space syntax is grounded in the mathematics of graph theory but through its clear visualisations (see Figure 2 for an example) also speaks to lay people in representing, for example, visibility relationships. This analytical process thus facilitates reflection on the non-discursive properties of space. Hillier explains this as "bringing (...) the non-discursive, configuration dimension of built form (...) to reflective awareness and abstract exploration" 3 . 


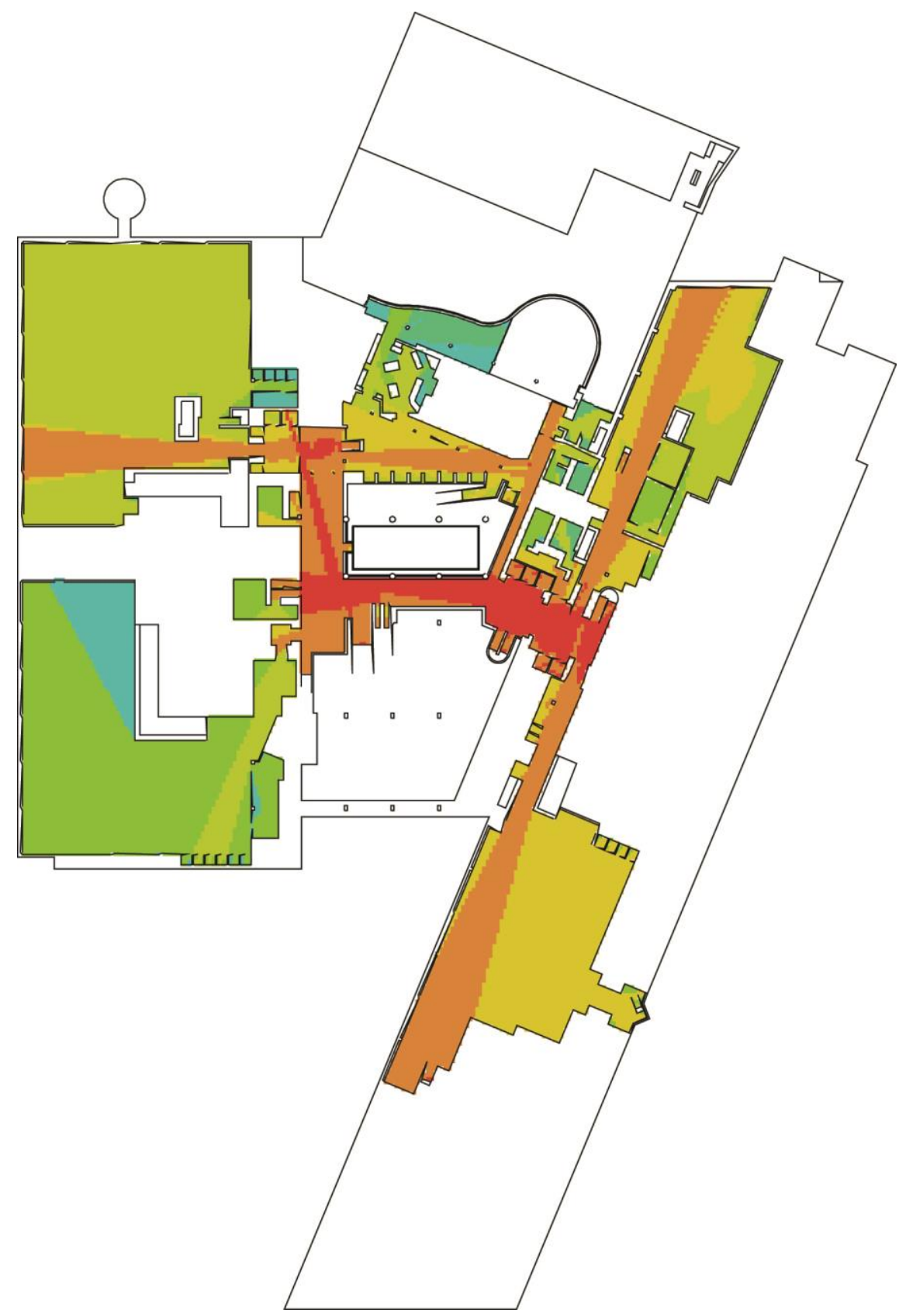

Figure 2: Visualisation of spatial relationships of visibility in the $1^{\text {st }}$ floor of the British Library; areas of shorter visible paths through the building are highlighted in warm colours whereas more segregated places are shown in cooler colours [Source: Analysis by Kerstin Sailer in depthmapX]

While traditionally, space syntax considers the generic patterns of human behaviour as "relations between configurations of people and configurations of space" ${ }^{3}$, more recent approaches highlight how a configurational theory of space can be adapted for the interpretation of specific cultural and historical contexts. This implies a critique of space syntax theory for lacking sensitivity to temporal processes and focusing on an ahistorical 'generalised individual' ${ }^{2}$. There is also an increasing body of syntactical work addressing spatial practices and the experience of everyday social life ${ }^{13,14}$. Other research emphasises the individual and psychological experience of space through studies of way-finding ${ }^{15}$, examining how the spatial layout has an 
impact on cognitive processes of art viewers ${ }^{16}$, and how different groups of people experience and use the same space differently in complex buildings ${ }^{17}$.

\section{A syntactical perspective on conscious design}

From its inception space syntax was not just an analytical method but a theory and 'tool to think with' ${ }^{18}$. Due to its claims to accurately predict movement and encounter patterns, and close links to commercial design and consultancy practices, it has sometimes been accused of spatial determinism ${ }^{19}$. This is not entirely fair. Hillier's position is that spatial layout is seen to generate a field of 'probabilistic encounter' 20 rather than determining behaviour. Even so, space syntax is eyed suspiciously by some scholars, especially in the field of human geography, which has, arguably, grown 'afraid of physical space' in reaction to the perceived inadequacies of quantitative methods in social studies ${ }^{21}$. We would argue that the ongoing development of space syntax as a discipline shows considerable flexibility as to exactly how it might be implemented in evidence-based design ${ }^{22,23}$. A syntactical lens aids general understanding of phenomena and may inform the decision-making process yet it does not directly dictate a design solution.

In the field of workplace environment research it has been argued that predictability, (i.e. confidently inferring insights into social behaviours of a yet unknown case through investigating a series of comparable other cases), is not easily established 24. Even with a large comparative data set variation is too high to allow for predictions. This means evidence-based design cannot rely on data to point to concrete solutions. Data is not a decision-making device but a tool to think with, as suggested by author Scott Berkun:

"Data can't decide things for you. It can help you see things more clearly if captured carefully, but that's not the same as deciding." 25

This open-ended use of data in design could be closely aligned with the idea of conscious design - to the extent that it identifies possibilities in the building layout or the social use of the building that can form the basis for future adaptations.

'Conscious' can be defined ${ }^{1}$ as perceiving, apprehending or noticing something with a degree of controlled thought or observation and acting with critical awareness. Translated into the realm of design, a conscious design process is one in which a social or spatial phenomenon is understood ('perceived') through systematic and rigorous enquiry ('controlled thought or observation'), which makes knowledge available for critical evaluation ('awareness') and therefore discursive.

An example of conscious design in this sense is supplied by the British Library, designed by its architect Sir Colin St John Wilson as a building that welcomes a diversity of people and usage processes. The building has been described by critics as one that "seeks relationships with the individuals who use it and visit it, through a sense of invitation [...] to be a participant, not merely a spectator" ${ }^{26}$, and a building that allows usage to be an "individual intimate act" 27 . A syntactic analysis of the spaces of the British Library by Sailer ${ }^{17}$ highlights how the building structures and distributes social activities; for instance observation showed how laptop users preferred smaller and more centrally located areas, especially if they were also talking, while in contrast those laptop users reading in parallel sat in larger and more

${ }^{1}$ http://www.merriam-webster.com/dictionary/conscious (Last accessed: 24th October 2016) 
segregated spaces. At the weekends, laptop users in general moved to more socially active locations that were again smaller and more centrally located. It was concluded that the building presented a "layered, dynamic and changing experience rather than [...] a definite entity impacting collective user behaviour in one particular way" 17.

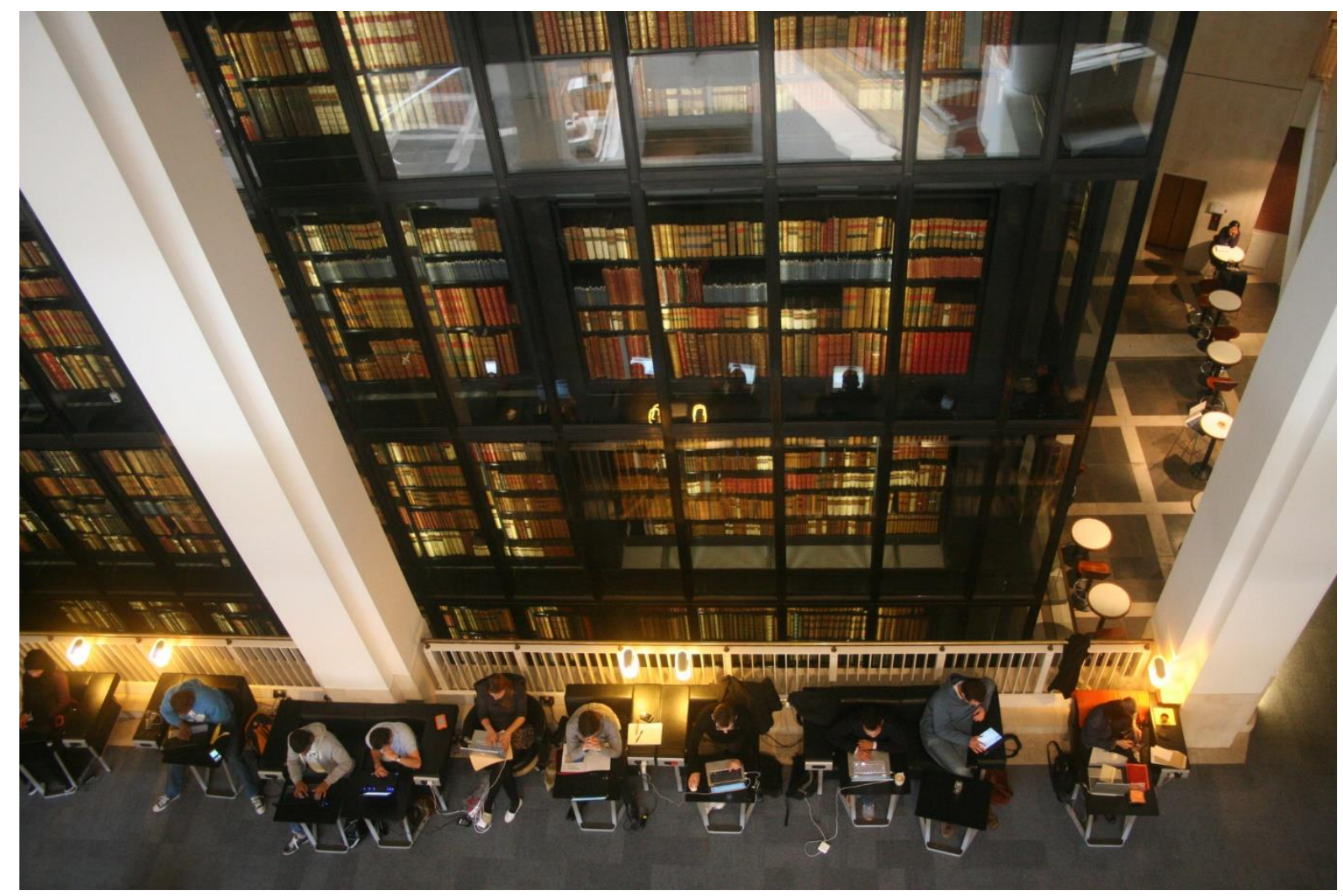

Figure 3: Laptop users in the British Library [Source: Kerstin Sailer]

No direct design advice was generated out of these findings, nevertheless, intuitively the British Library has over the years continuously changed their space provision to account for the increasing phenomenon of mobile workers (see figure 3 ). For instance, more desks have been installed in the publicly accessible corridors (small but central locations) to cater for people working on their laptops without accessing the Library's collections through the reading rooms. In this sense, the British Library is an example of a conscious design process, one that is aware of social and spatial phenomena and intervenes in accordance with shifts in everyday spatial practices.

Hillier ${ }^{3}$ claims space syntax is a "configurational paradigm of architecture" with design founded on the "rational deployment of intuition". It offers a process by which the intuitive can be transformed into discursive knowledge through a process of analysis, visualization and interpretation. The ability to visualise and name spatial relationships offers a powerful way of bringing the social qualities of space to light in the design process, that may otherwise remain uncommunicated in the domain of intuitive perception. Using these insights not in a prescriptive, but an exploratory way can help guide conscious design rather than determine fixed solutions. 


\section{References}

1 Forty, A. Words and Buildings. A Vocabulary of Modern Architecture. (Thames and Hudson, 2000).

2 Pfeifer, R. \& Bongard, J. How the body shapes the way we think : a new view of intelligence. (MIT Press, 2007).

3 Hillier, B. Space is the machine. A configurational theory of architecture. (Cambridge University Press, 1996).

4 Giddens, A. The Constitution of Society. Outline of the Theory of Structuration. (Blackwell Publishers, 1984).

5 Gregory, D. \& Urry, J. in Social Relations and Spatial Structure (eds Derek Gregory \& John Urry) Ch. 1, 1-8 (Macmillan Publishers, 1985).

6 Feldman, M. S. \& Orlikowski, W. J. Theorizing Practice and Practicing Theory. Organization Science 22, 1240-1253, doi:10.1287/orsc.1100.0612 (2011).

7 Orlikowski, W. J. Sociomaterial Practices: Exploring Technology at Work. Organization Studies 28, 1435-1448, doi:10.1177/0170840607081138 (2007).

8 Shove, E., Pantzar, M. \& Watson, M. The Dynamics of Social Practice: Everyday life and how it changes. (Sage Publications Ltd, 2012).

9 Crang, M. \& Thrift, N. (Routledge, London and New York, 2000).

10 Hillier, B. Space and spatiality: what the built environment needs from social theory. Building Research \& Information 36, 216-230, doi:10.1080/09613210801928073 (2008).

11 Hillier, B. \& Hanson, J. The social logic of space. (Cambridge University Press, 1984).

12 Griffiths, S. Temporality in Hillier and Hanson's Theory of Spatial Description: Some Implications of Historical Research for Space Syntax. The Journal of Space Syntax 2, 73-96 (2011).

13 Griffiths, S. \& Netto, V. M. Open Syntaxes: Towards new engagements with social sciences and humanities. Guest Editorial. The Journal of Space Syntax 6, i-v (2015).

14 Griffiths, S. \& Von Lünen, A. (Routledge, London and New York, 2016).

15 Carlson, L. A., Hölscher, C., Shipley, T. F. \& Conroy Dalton, R. Getting Lost in Buildings. Current Directions in Psychological Science 19, 284-289, doi:10.1177/0963721410383243 (2010).

16 Krukar, J. Walk, Look, Remember: The Influence of the Gallery's Spatial Layout on Human Memory for an Art Exhibition. Behavioral Sciences 4, 181 (2014).

17 Sailer, K. The dynamics and diversity of space use in the British Library. ITU A/Z Journal of the Faculty of Architecture 12, 23-39 (2015).

18 Hillier, B. \& Hanson, J. in 1st International Space Syntax Symposium. (eds Mark David Major, Luiz Amorim, \& Francois Dufaux) 1.1-1.5 (Space Syntax Laboratory, University College London).

19 Till, J. The broken middle: The space of the London riots. Cities 34, 71-74, doi:http://dx.doi.org/10.1016/i.cities.2012.01.004 (2013).

20 Hillier, B., Burdett, R., Peponis, J. \& Penn, A. Creating life: Or, does architecture determine anything? Architecture and Behaviour 3, 233-250 (1987).

21 Sailer, K. in Learning Organizations. Extending the Field Knowledge and Space. Volume 6. (eds Ariane Berthoin Antal, Peter Meusburger, \& Laura Suarsana) 103-127 (Springer, 2014).

22 Sailer, K., Pomeroy, R. \& Haslem, R. Data-Driven Design - Using Data on Human Behaviours and Spatial Configuration to Inform Better Workplace Design. Corporate Real Estate Journal 4, 249-262 (2015).

23 Sailer, K., Budgen, A., Lonsdale, N., Turner, A. \& Penn, A. in Undisciplined! Proceedings of the Design Research Society Conference 2008 (eds David Durling et al.) (Sheffield Hallam University, available online <http://shura.shu.ac.uk/492/>, Sheffield/UK, 2008).

24 Sailer, K., Koutsolampros, P., Zaltz Austwick, M., Varoudis, T. \& Hudson-Smith, A. in Architecture and Interaction: Human Computer Interaction in Space and Place (eds S. Nicholas Dalton, Holger Schnädelbach, Mikael Wiberg, \& Tasos Varoudis) 137-161 (Springer International Publishing, 2016).

25 Berkun, S. The year without pants : WordPress.com and the future of work. (Jossey-Bass, 2013).

26 MacCormac, R. in The Architecture of the British Library at St Pancras (eds Roger Stonehouse \& Gerhard Stromberg) xii-xiv (Spon Press, 2004).

27 Stonehouse, R. in The Architecture of the British Library at St Pancras (eds Roger Stonehouse \& Gerhard Stromberg) 43-79 (Spon Press, 2004). 